\title{
Professional Caregivers' Perceptions on how Persons with Mild Dementia Might Experience the Usage of a Digital Photo Diary
}

\author{
Christina Harrefors ${ }^{*}$, , Stefan Sävenstedt ${ }^{1}$, Anders Lundquist ${ }^{2}$, Bengt Lundquist ${ }^{2}$ and Karin Axelsson ${ }^{1}$ \\ ${ }^{I}$ Department of Health Science, Luleå University of Technology, Luleå, Sweden \\ ${ }^{2}$ Department of Statistics, Umeå University, Umeå, Sweden
}

\begin{abstract}
Cognitive impairments influence the possibility of persons with dementia to remember daily events and maintain a sense of self. In order to address these problems a digital photo diary was developed to capture information about events in daily life. The device consisted of a wearable digital camera, smart phone with Global Positioning System (GPS) and a home memory station with computer for uploading the photographs and touch screen. The aim of this study was to describe professional caregiver's perceptions on how persons with mild dementia might experience the usage of this digital photo diary from both a situation when wearing the camera and a situation when viewing the uploaded photos, through a questionnaire with 408 respondents. In order to catch the professional caregivers' perceptions a questionnaire with the semantic differential technique was used and the main question was "How do you think Hilda (the fictive person in the questionnaire) feels when she is using the digital photo diary?". The factor analysis revealed three factors; Sense of autonomy, Sense of self-esteem and Sense of trust. An interesting conclusion that can be drawn is that professional caregivers had an overall positive view of the usage of digital photo diary as supporting autonomy for persons with mild dementia. The meaningfulness of each situation when wearing the camera and viewing the uploaded pictures to be used in two different situations and a part of an integrated assistive device has to be considered separately. Individual needs and desires of the person who is living with dementia and the context of each individual has to be reflected on and taken into account before implementing assistive digital devices as a tool in care.
\end{abstract}

Keywords: "Ageing in place", assistive digital device, dementia, factor analysis, perceptions.

\section{INTRODUCTION}

An ongoing discourse is taking place about the possibility and importance of using Information and Communication Technology (ICT) to meet the needs and support the quality of life of an increasing number of elderly people. This, among other things, was manifested in the Ambient Assisted Living Roadmap of the EU's seventh framework programme [1]. In this discourse, the possibility of developing cognitive digital assistive technology to support "aging in place", having the possibility to live at home for as long as possible, for people with dementia living in their private homes and their carers is of special interest [2]. This can be seen as a way of supporting well-being and person-hood cf [3]. There is documented experience, however, that the introduction of new ways of providing support for elderly people, such as the use of ICT solutions, is often resisted by professional caregivers because of their perceptions and values [4]. For people with dementia, professional caregivers' perceptions about the use of digital Assistive Technology (AT) devices is of importance, since the carer has the power to suggest or decide about access. Professional carers' perceptions are built on knowledge about the disease, experiences of the limitations and benefits of assistive digital devices, along with values related to the use of assistive digital devices.

*Address correspondence to this author at the Department of Health Science, Luleå University of Technology, 97187 Luleå, Sweden;

Tel: +46921 491000; E-mail: christina.harrefors@ltu.se

\section{BACKGROUND}

For people with cognitive problems, the maintenance of the sense of self, and consequently a sense of dignity, is a desirable goal and a fundamental base for the experience of well-being. A common and central concept in understanding the sense of self of people with dementia is "personhood", defined as being a human. Being understood to be someone unique is something that strengthens the feeling of being a human and is a prerequisite for human encounter [3]. The importance of maintaining the feeling of being a human is described in several studies conducted with people living with dementia as one of the most major concerns in their daily lives. This is very closely associated with maintaining control and independence [5], not being treated as a syndrome, "the disease" [6], receiving understanding and support from relatives and being listened to with respect [7]. Moreover, being able to perform or participate in meaningful activities, which enable the person with dementia to experience feelings of pleasure and enjoyment; feeling a sense of connection and belonging; and retaining a sense of autonomy and personal identity [8]. For a long time, a person's life story and different forms of memory support have been used to assist people suffering from dementia. Mc Keown et al., [9], for example, described how collecting different aspects from earlier life and from a person's current life is a way to facilitate the maintenance of the life story, with the purpose being to support people in their actual situation. The life story is described as having the potential to enhance person-centred care for people suffering from dementia in their surroundings [10]. The work is often 
collaboration between relatives or significant others and the result can be, for example, pictures, collage or a collection of memory books. If it is possible to catch the life story of a person with dementia, it is necessary to start examining the story in time, that is, while the person is still able to present her/his own picture of her/his life [11, 12]. Basset and Graham [13] stated that there is a possibility of maintaining the identity of persons with cognitive impairment by regularly working with their life stories. A person's life story, identity and sense of self is connected to persons, places, events and objects and it can be assumed that the experience of home plays an important role in the life story.

The basis for the discussion about the benefits of "aging in place" is the assumption that the home is experienced to be an invaluable resource and a special place of overriding importance when aging [14-16]. The home is highly valued and, for the person living in it, it means, among other things, security and freedom [16]. One way of supporting older people who want to age in place in their own home is to explore the possibilities of using specific assistive digital devices to support independence and promote well-being [17]. One can assume that a person who receives a diagnosis of dementia will probably strive to continue to live at home for as long as possible, to continue to have the possibility of independent living and maintain an ordinary way of life, including, for example, the ability to go out shopping, take a walk in familiar surroundings and to engage in enjoyable informal interactions with friends and neighbours, $c f$. [18]. For a person with dementia the use of digital assistive technology might contribute to enhanced independence, wellbeing and a feeling of being autonomous [19]

Values like self-determination have a central role when a person is in need of support, especially when the support and care is given at home. Self-determination is a central aspect of autonomy and is something that can be exercised even under changed and restricted circumstances as long as there is a possibility of making decisions from a set of alternatives that can be offered in whatever the surroundings, even if they are outside the home [20].

New AT is becoming increasingly readily available in society as a whole, also could have an impact on elderly people living at home [21]. There is an emerging field of research that indicates that the provision of AT when getting older can play a role in facilitating daily living [22, 23]. For example, like supporting the independence of, providing a sense of security to and increasing the feeling of well-being of people with dementia and their relatives [24]. Independence and feeling secure are often mentioned as important and desirable states of existence, which the use of AT has the potential to contribute to [23-25]. When healthy elderly people were asked about their perceptions about the use of AT in the event of them becoming dependent on care, they expressed mixed feelings on an individual basis, they could see that there would be positive and negative sides to the use of assistive technology services [26]. Some studies indicated that, for people with dementia, the use of AT is a complex issue that involves prejudices and conflicting feelings. There is a fear that the increased use of ICT might contribute to inhuman care with a loss of dignity, and at the same time be a promoter for human care $[4,26]$, thereby helping to ensure that certain values are maintained as others are lost. This is a complex issue and a vital one if standards are to be ensured. As people with mild dementia described having technology-related concerns when using both the more-familiar technology like televisions, and new technology like computers and cell phones, there is a need for these people to receive support with technologies at home and out in society [27].

A review of the literature shows that research conducted up to now about the possibility of supporting people with mild dementia in their private homes through the use of AT has only been studied to a limited extent. More research is needed focusing on enabling persons with early-stage dementia to continue to live in their homes for as long as possible [2]. Therefore it is of great importance to explore professional caregivers' perceptions, and through this, to comprehend the values that are associated with the use of a specific assistive digital device to support the life-stories for people living with dementia. The use of AT to support and maintain a person's life-story in different ways is a rather new phenomenon and needs to be studied carefully and evaluated.

This study falls within the boundaries of a project where a new assistive digital device to support the maintenance of the life-stories of persons in the early stage of dementia is tested [28]. The device was developed to capture information about daily life events, and enables the information to be retrieved in a context-dependent manner subsequently. The tested assistive digital device in the project is comprised of three different components, a digital wearable camera, a computer and a smart phone, as clarified (Table 1). The camera is worn around the neck with a cord and takes photographs automatically that are uploaded onto the computer later on. The smart phone has a Global Positioning System (GPS) and collects information about the places visited. A computer with a touch screen is placed in the home and, together with a relative or member of staff, it is possible for the person with dementia to review and discuss the events of the day with the aid of the photos. All information is for personal use, and no one can access the collected information. Through the regular reviews conducted, a digital library of information is built-up that serves as a digital photo diary on which to build and maintain a life-story that includes the past and the present.

\section{AIM}

The aim of this study was to describe caregiver's perceptions of how persons with mild dementia are likely to experience the usage of a specific digital photo diary.

\section{METHOD}

The research collection strategy presented here took the form of a questionnaire, and was conducted in Sweden with caregivers involved in or responsible for the care of people living with dementia.

\section{The Questionnaire}

The questionnaire, specifically constructed by the authors for this study, was based on three dimensions security/control, freedom/autonomy, and integrity/dignity. These dimensions were identified as being of importance when implementing new technology in care of people with 
Table 1. Descriptions of the Three Components of the Digital Photo Diary Used in the Research Project and in Focus in this Study

\begin{tabular}{|c|c|c|}
\hline Device Detailed & Application & Technical Function \\
\hline \hline $\begin{array}{c}\text { Digital Wearable } \\
\text { Camera }\end{array}$ & For daily use at home or outdoors & $\begin{array}{c}\text { Taking photographs automatically annotating them with the } \\
\text { time and date }\end{array}$ \\
\hline $\begin{array}{c}\text { Computer with } \\
\text { Touch Screen }\end{array}$ & $\begin{array}{c}\text { For daily use with the assistance of a relative or carer } \\
\text { To look at photographs which show the people that the person } \\
\text { with dementia has met during the day and at which places }\end{array}$ & $\begin{array}{c}\text { Stores photographs and sorts them according to groups of } \\
\text { people, places and time }\end{array}$ \\
\hline Smart Phone & For daily use at home or outdoors together with the camera & Detects position by Global Positioning System (GPS) \\
\hline
\end{tabular}

dementia, a conclusion of the EU Biomed II Project, Technology, Ethics and Dementia [29]. The same dimensions were also interpreted as being of importance for elderly people when they in interviews discussed the use of the services that assistive technology can provide when they are in need of care [26]. These dimensions, privacy, autonomy and safety were also defind as the most important ethical considerations in the field of AT in care for community-dwelling elderly people with dementia [30]. The questionnaire was based on a scenario. The scenario incorporated photographs presenting a newly retired woman living with mild dementia (Hilda), showing a realistic picture of how the device was anticipated to work in her daily life.

A series of questions divided in parts was presented in conjunction with this. Part I of the questionnaire consists of personal data relating to the respondent and his or her worksituation. Parts II and III were designed using a semantic differential (SeD) technique developed by Osgood and comprises a number of bipolar adjectives to measure values about a phenomenon, person or event [31]. The SeD technique method has been found to be valid and reliable for assessing the affective meaning of concepts and provides a way of quantifying attitudes that are not measurable in a direct way [32] and used to measure nurses' attitudes towards people with dementia [33] and nurses' attitudes towards inpatients in psychiatric care [34]. The overall question asked in parts II and III was: "What feelings do you think the person with dementia (Hilda) associates with carrying the digital camera and the smart phone (part II), and What feelings to do you think the person with dementia (Hilda) associates with viewing and sorting the photographs whilst sitting in front of the computer (part III)?" The respondents stated their responses on a seven-point scale ranging from e.g. "safe" (1) to "unsafe" (7). In the bipolar adjectives, the left side of the questionnaire contained positive adjectives, and the right side, negative ones. The lower the score, the more positive the evaluation of the use of the assistive digital device; the higher the score, the more negative the evaluation. A midline score indicated a neutral evaluation. The same items were used in both parts II and III. Part IV contains both negative and positive statements about the consequences of using the digital photo diary and part $\mathrm{V}$ concerned statements about prerequisites for using the digital photo diary. In both part IV and V, a five point scale, ranging from strongly agree (1) to strongly disagree (5) was used. The last part V of the questionnaire included an openended question about important aspects of the digital photo diary.

The semantic aspects of the different sections of the questionnaire was discussed with a researcher working on semantics in the Swedish language, revisions were made to several different statements. To assess the 'face validity' of the questionnaire six researchers with experiences of constructing questionnaires were asked to give their opinions. Clarifying information was elicited about the appropriate wording of items. The items were discussed, thereafter revised or deleted based on the researchers' comments.

To assess the construct validity of the questionnaire it was sent out to seventy registered nurses (response rate 84 $\%$ participating in specialist training programmes for the care of the elderly and district nursing with a request to complete the survey instrument. In the analysis, the Statistical Package for Social Science (SPSS) for Windows, version 18.0 was used. The Kaiser-Meyer-Olkin (KMO) test for the three different parts was $>0.5$, which indicated to go on with the factor analysis. As a first step of the factor analysis a principal component analysis (PCA) was made to test the congruence between the measured items and the underlying structure, for each one of the three parts of the questionnaire. The unrotated PCA for the parts in the questionnaire yielded 3-5 factor solutions with an eigenvalue $>1$. The explained variance in the different parts ranged from $71.5-76.0 \%$. All items in part II and III loaded fairly high, $>0.5$, in part IV $>0.4$, exceeding the criterion level of 0.40 or higher recommended [35]. The internal consistency of different aspects of the assistive digital device was measured by Cronbach alpha, and was for the three parts $0.961,0.967$ and 0.645 respectively. Coefficients of reliability of 0.7 or higher are generally desirable [35]. Even if one part of the questionnaire had a coefficient $<0.7$, the results in the pilot test were interpreted as we had reached a construct validity of the questionnaire and a good reliability.

In all steps of the validation process, comments from the participants were considered and included in the final version of the questionnaire, containing 79 items for further use (Table 2).

\section{Participants}

To achieve a study population of professional caregivers in Sweden, a systematic selection was made by choosing to contact one third (97) of all municipalities in Sweden (290) by using an alphabetic registry, www.webor.se. The sizes of the different types of municipalities were well represented. In an initial telephone call with each municipality, a person responsible for the care of the elderly was given information about the study and the assistive digital device assessed in 
Table 2. The Description of the Questionnaire*

\begin{tabular}{|c|c|c|}
\hline Parts & Content & No of Items \\
\hline \multirow{7}{*}{ Part I } & Backgrounds questions & 8 \\
\hline & Gender & \\
\hline & Education & \\
\hline & Present position & \\
\hline & Time working at present position & \\
\hline & Experience of working with people with dementia & \\
\hline & Use of computer at leisure time & \\
\hline Part $V$ & Statements about prerequisites for using the digital photo diary, 5 point scale from strongly agree - strongly disagree, & 5 \\
\hline Part VI & Open ended question about further important aspects of using the digital photo diary & 1 \\
\hline Total & & 79 \\
\hline
\end{tabular}

*The same bipolar adjectives were used in the part II and III.

this project. The information also included the approximate time to complete the questionnaire, about 30-40 minutes. These key persons were asked about the possibility of participating in the study and also requested to choose six persons/people in their organization to complete the questionnaire. The inclusion criteria given to the key person were: being professional care personal with experience of people living with dementia and of working with them and having a direct ability to influence the access to devices for these persons. Ten municipalities declined participation in the study, generally stating lack of time as the primary reason, so ten new municipalities were recruited to replace them. If, after receiving the questionnaire, as a printed form, the respondents had some concerns related to the questions, they were welcome to contact the researcher for further information and had been informed of this. The questionnaires were marked with a code for the municipality and one reminder was sent out to the key person, designated as the person spoken to by telephone if responses were missing.

The questionnaire was sent out/distributed to a total of 582 participants, with 408 responding. The response rate was $70 \%$ (Table 3).

\section{Data Analysis}

To characterize the study participants, we used descriptive statistics (Table 3). The same procedure used to analyze the data in the pilot study was used in original study to elucidate the relationship between the variables in the questionnaire. The Kaiser-Meyer-Olkin (KMO) measure of sampling adequacy was high, for the conducted tests, $>0.5$. To explore the dimensionality of the scale, we began with a principal component factor analysis and determined the factor loadings. We then used the varimax method with Kaiser normalization to rotate the initial factor and determine the communalities. We scrutinized our factor loadings, interpreted and labelled them based on the included items. By using factor analysis (FA), it is possible to describe the variance of the observed manifest variables in terms of a lower number of unobserved variables; therefore the method is commonly used when there is a need to reduce a large numbers of observed variables to a more manageable quantity. The analysis process was made in several steps, first a separate analysis of the responses to the situations of using the camera and smart phone (part II) and using the computer viewing uploaded pictures (part III). Thereafter another factor analysis of the two situations was made where some of the included items were excluded, in order to facilitate a comparison of the revealed factors from the first step. The internal consistency of the instrument was measured by using Cronbach's alpha coefficient. A multivariate analysis of the covariance, MANCOVA, was used to see the main and interaction effects of categorical variables on multiple dependent interval variables [35].

\section{Ethics}

Participation in the study was voluntary and the questionnaires were answered anonymously. The study was approved by the Regional Ethical Review Board in Umeå, Sweden (Dnr 09-132M).

\section{RESULTS}

The results focus on the background questions (part I), and concern what the informants believed the fictive person (Hilda) in the questionnaire felt when wearing the camera at home and outdoors (part II), and what the informants believed the fictive person (Hilda) in the questionnaire felt when viewing and sorting the uploaded photos while sitting in front of the computer with a relative (part III). 
Table 3. Response Rate and Descriptions of the Participants

\begin{tabular}{|c|c|c|c|}
\hline Backgrounds Questions & Total $(n)$ & Percent (\%) & Male/Female ( $n$ ) \\
\hline Number of questionnaires distributed & 582 & 100 & \\
\hline Dropouts & 174 & 29.9 & \\
\hline \multicolumn{4}{|l|}{ Present position } \\
\hline Registered nurse & 106 & 25.9 & $3 / 103$ \\
\hline Occupational therapist & 61 & 15.0 & $1 / 60$ \\
\hline Physiotherapist & 11 & 2.7 & $2 / 9$ \\
\hline Assistant nurse & 77 & 18.9 & $2 / 75$ \\
\hline $20-29$ & 18 & 4.3 & $3 / 15$ \\
\hline $30-39$ & 63 & 15.7 & $3 / 60$ \\
\hline $40-49$ & 121 & 29.6 & $3 / 118$ \\
\hline $50-59$ & 143 & 35.0 & $6 / 137$ \\
\hline $60-69$ & 55 & 13.4 & $2 / 53$ \\
\hline Missing data & 8 & 2.0 & \\
\hline
\end{tabular}

* Data missing for 8 respondents.

\section{Comparison Between Perceptions About Using the Two Different Applications}

When making a comparison of the results of the preliminary factorial analysis of the two applications, wearing the camera and viewing uploaded photographs, it was obvious that there were almost the same variables included in the factors but in different order. This reflects that the digital photo diary service consisted of two separate devices. In order to further analyse similarities and differences between the two situations of using the digital photo diary the following bipolar adjectives; cozy/worse, energetic/lethargic, cherished/abandoned, confirmed/unconfirmed, and satisfied/dissatisfied were excluded since they were judged as concepts that are difficult to attribute to one single factor.

The results from the FA of wearing the camera (part II) revealed a three factor solution, with an eigenvalue $>0.9$. In the analysis of part III, viewing the uploaded photos, we decided to also extract three factors even if the eigenvalue was $<1$ (the lowest 0.7 ). In both analyses the same factors appeared in the same order (Table 4). As the questions in the questionnaire where asked "What feelings do you think ... etc", the factors from the FA were given the name "Sense of ... etc". The factors were interpreted and labeled as Sense of autonomy, Sense of self-esteem and Sense of trust, Sense of autonomy is the first and most important factor that revealed from the factor analysis with an explained variance of $61 \%$ in part II and $65 \%$ in part III. The mean value was 3.25-3.61 and 3.18-3.47 respectively and the result means a tendency that the participants in the study perceived that autonomy would be supported for people with dementia by using the digital photo diary. Sense of self-esteem, ranged an explained variance of 5-6\% and the mean value for the different parts was 2.68-2.91 and 2.42-2.80 respectively. From the assessments it can be seen that the use of the device is perceived to contribute to self-esteem for people with dementia. Sense of trust, the mean value ranged 3.11-3.32 and 3.18-3.31 and is an expression of a positive view; the digital photo diary is perceived to provide a sense of trust.

The Cronbach's alpha coefficient for the items when wearing the camera ranged between 0.912-0.916, and in the part viewing photos in the home memory station ranged between 0.921-0.941. The values of all coefficients are suggesting good internal consistency.

\section{Differences in Factors Scores Between Different Positions and Gender when Using the Camera}

A MANCOVA was performed using age as a covariate to investigate if there were any differences in the factor scores between different positions and/or the gender of the caregivers. The interaction between 'present position' and 'gender' was significant $(\mathrm{p}<0.0005)$. Both 'gender' $(p=0.048)$ and 'present position' $(p<0.0005)$ were also significant as main effects in the multivariate tests, although 'gender' is a borderline case. The numbers of men who responded to the survey were few, 17 of a total 408 . The interaction between 'gender' and 'present position' mainly consist of a lack of variation in factor scores between different work categories for men, i.e. men have practically the same factor scores across all work categories, which is not the case for women. Due to the small number of men in the sample we think it is still appropriate to present results regarding the main effect for 'present position', which is 
Table 4. The Results from the Factor Analysis with Reduced Variables, Concern Both Wearing the Camera and Viewing and Sorting Photographs

\begin{tabular}{|c|c|c|c|c|c|c|c|}
\hline Variables - Wearing the Camera & 1 & 2 & 3 & Variables - Viewing and Sorting Photographs & 1 & 2 & 3 \\
\hline Sense of Autonomy & & & & Sense of Autonomy & & & \\
\hline Independent/Dependent & .782 & & & Independent/Dependent & .827 & & \\
\hline Competent/Incompetent & .731 & & & Free/Constrained & .792 & & \\
\hline Healthy/Unhealthy & .685 & & & Healthy/Unhealthy & .761 & & \\
\hline Successful/Unsuccessful & .675 & & & Competent/Incompetent & .712 & & \\
\hline Free/Constrained & .675 & & & Successful/Unsuccessful & .689 & & \\
\hline Oriented/Disoriented & .665 & & & Oriented/Disoriented & .645 & & \\
\hline Comfortable/Uncomfortable & .546 & & & Comfortable/Uncomfortable & .542 & & \\
\hline Sense of Self-esteem & & & & Sense of Self-esteem & & & \\
\hline Important/Uninportant & & .806 & & Important/Uninportant & & .792 & \\
\hline Selected/Overlooked & & .731 & & Worthy/Worthless & & .770 & \\
\hline Worthy/Worthless & & .720 & & Selected/Overlooked & & .762 & \\
\hline Active/Passive & & .669 & & Active/Passive & & .737 & \\
\hline Social/Antisocial & & .646 & & Social/Antisocial & & .724 & \\
\hline Strengthened/Diminished & & .581 & & Strengthened/Diminished & & .611 & \\
\hline Sense of trust & & & & Sense of trust & & & \\
\hline Safe/Unsafe & & & .853 & Secure/Insecure & & & .824 \\
\hline Secure/Insecure & & & .853 & Safe/Unsafe & & & .798 \\
\hline Calm/Worried & & & .691 & Calm/Worried & & & .634 \\
\hline Trusting/Suspicious & & & .547 & Trusting/Suspicious & & & .618 \\
\hline Eigenvalue & 10.428 & .995 & .957 & & 11.152 & 1.180 & .748 \\
\hline Percent of variance & 61.341 & 5.853 & 5.628 & & 65.601 & 6.941 & 4.400 \\
\hline Cronbach' alpha & .912 & .915 & .916 & & .930 & .941 & .921 \\
\hline
\end{tabular}

done in the following. Further, since 'gender' is on the border of significance and the sample sizes for men and women respectively are vastly different, we resist the temptation of making conclusive statements about gender differences.

The follow-up univariate analyses indicated that 'present position' had an impact on the score of the factors Sense of self-esteem and Sense of trust. Occupational therapists and physiotherapists had a significantly lower factor score compared to registered nurses and care administrators on the factor Sense of self-esteem (Fig. 1). This can be seen as occupational therapists and physiotherapists had a tendency to rate the included items in a more positive way than other positions. Furthermore, the occupational therapists and physiotherapists had a significantly higher average score than the group comprised of leaders, project leaders and care developer, and registered nurses on the factor Sense of trust (Fig. 2). This indicates that occupational therapists and physiotherapists have a tendency to disagree that the use of the camera can contribute to a sense of trust.

From the above presented results it is clear that occupational therapists and physiotherapists differ from the other positions on Self-esteem and Sense of trust. Even if it is not significant the assistant nurses have a tendency to agree that sense of self-esteem could be supported by using the camera.

\section{Differences in Factors Scores Between Different Positions and Gender when Viewing and Sorting the Uploaded Photos}

Differences in the factor scores between different positions occupied by and/or the gender of the caregivers were analyzed with a MANCOVA, using age as a covariate. The interaction between 'present position' and 'gender' was not significant at the $5 \%$-level $(\mathrm{p}=0.071)$ and was therefore excluded from the model. 'Present position occupied' was significant $(p=0.037)$ as a main effect in the multivariate tests, whereas 'gender' was on the border of significance $(p=0.052)$. For the same reasons as above regarding sample size differences for men and women, no conclusive statements about gender differences are made.

The follow-up univariate analyses indicated that 'present position' has an impact on the score of factor Sense of autonomy; the difference between leaders, project leaders and care developers, as one group, and occupational therapists and physiotherapists; and assistant nurses was significant. This result indicates that these groups of position seams to disagree that the sense of autonomy can be supported by viewing the uploaded photos. The care 


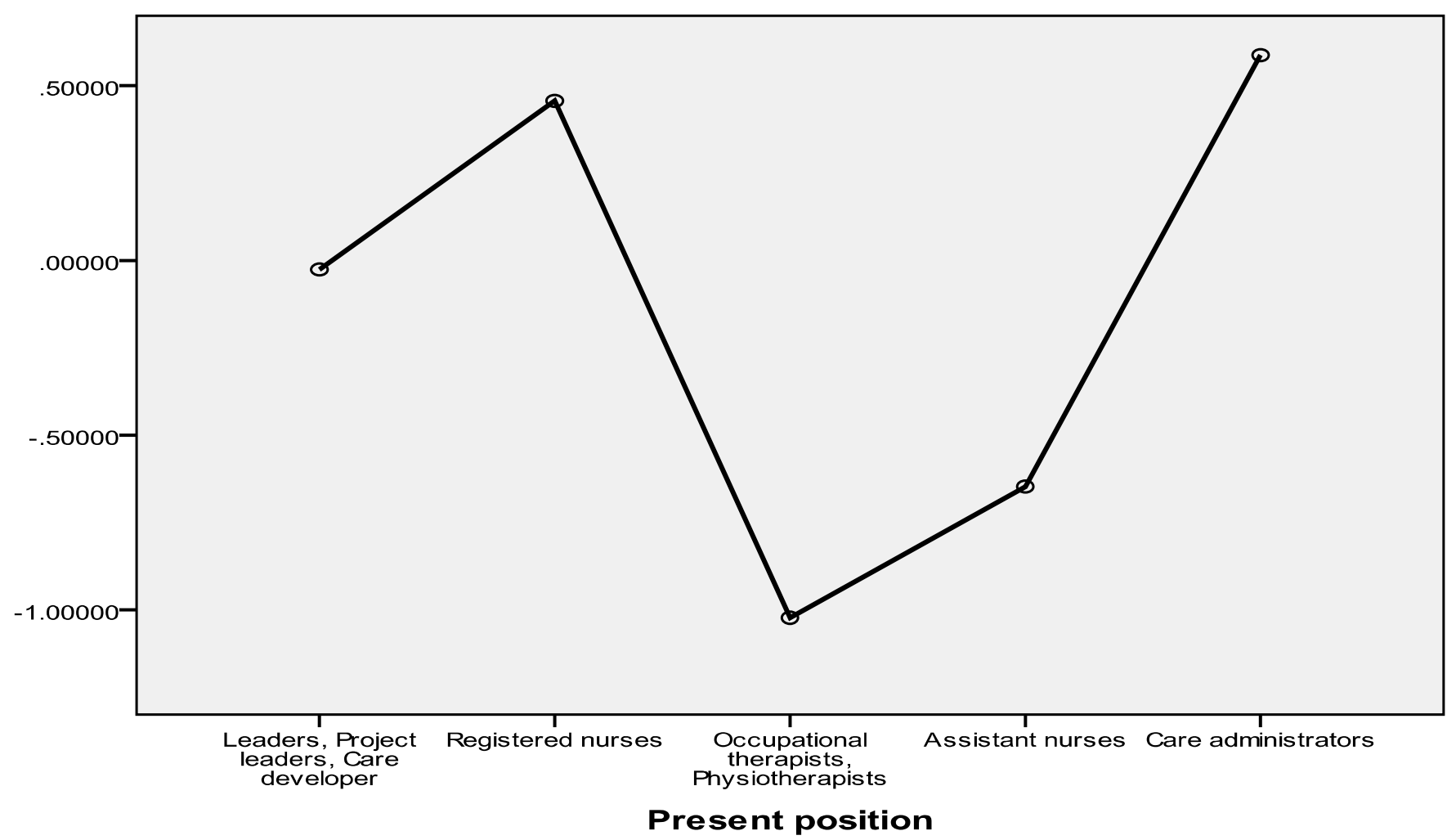

Fig. (1). The mean of the scores illustrates the impact of the present position occupied by the respondent on the factor Sense of self-esteem when wearing the camera and smart phone at home and outside.

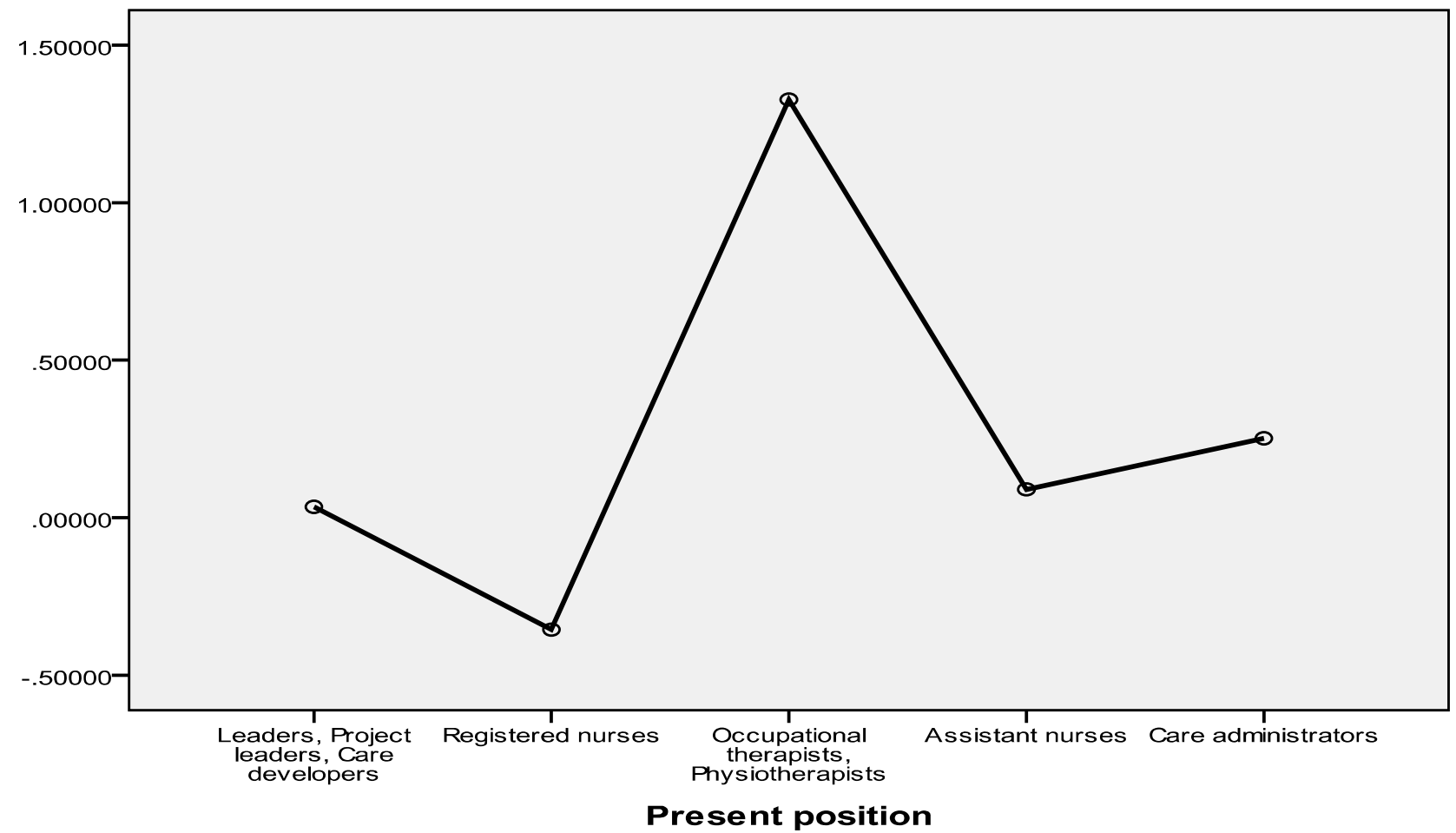

Fig. (2). The mean of the scores illustrates the impact of the present position occupied by the respondent on the factor Sense of trust when wearing the camera at home and outside.

administrators had lower score on the factor Sense of autonomy. It is interesting that occupational therapists and physiotherapists and assistant nurses are close to each other in their statements compared to the others position (Fig. 3). 


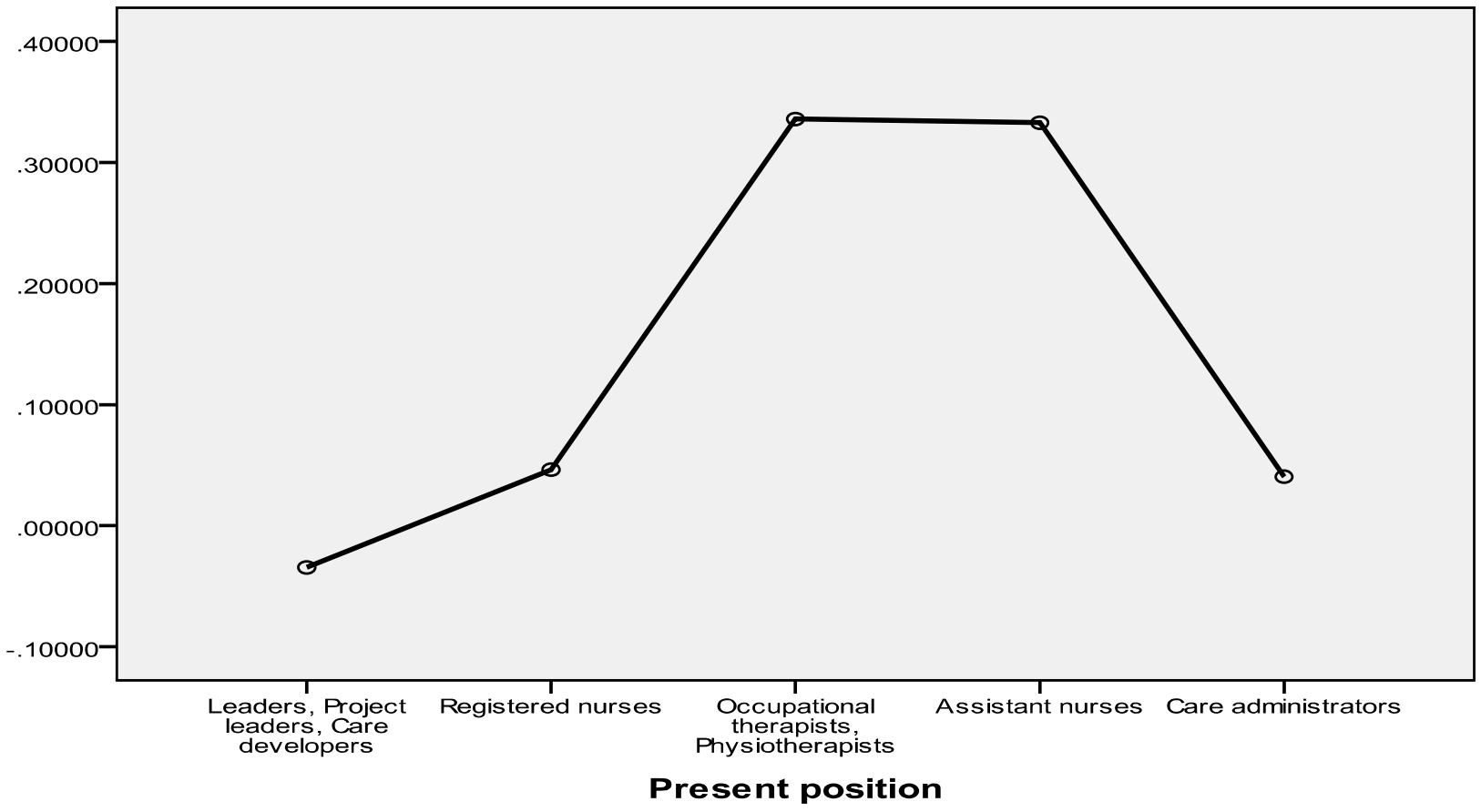

Fig. (3). Means of the score illustrate the impact of the present position occupied by the caregivers on the factor Sense of autonomy when viewing and sorting photos on the computer alongside a relative.

\section{DISCUSSION}

In order to clarify and elucidate the professional caregivers' perceptions on how persons with mild dementia might experience the usage of a specific digital photo diary, the professional caregivers were asked to rate their perceptions on a scale based on a semantic differential technique that comprised 22 bipolar adjectives. The results are interpreted as professional caregiver's view of using the digital photo diary was positive overall. The main finding from the factor analysis was that Sense of autonomy was the dominant factor from the both parts, wearing the camera and viewing and sorting photographs.

The interpreted factors Sense of autonomy, Sense of selfesteem and Sense of trust are all related to identity and perception of self. Sabat [36] has applied social construction theory to the analysis of selfhood in the conversational discourse of a person with mild to moderate dementia. Self is divided into three aspects in his work: the first aspect describes personal identity, the second describes mental and physical attributes, and the third one is connected to the self as a social person in interaction with others.

The factor Sense of autonomy, refers to the Sabat's second aspect of self, namely, describing mental and physical attributes [36]. Persons with dementia have difficulty remembering persons, places and events, and by documenting these with the camera and afterwards viewing and sorting the photos together with a relative, they could possibly manage to continue to be aware of what is happening to them despite their memory issues. The support obtained affecting maintaining control through the use of digital AT was also described by Engström et al., [37]. These authors stressed that, when people with dementia use communication technology as a support, it gives them a feeling of maintaining control and autonomy. Visiting familiar places, shopping and being able to perform activities of special personal interest all contribute to the well-being of people with dementia [18]. Furthermore, being able to maintain the memory of these persons, places and events through the documentation provided by the camera can contribute to enhanced sense of well-being and a feeling of strengthened self-esteem. By having the opportunity to use the digital photo diary and of being able to interact independently with others, the person could possibly perceive herself/himself as a competent valuable person who is in control; thereby strengthening the person's sense of self [36]. Losing autonomy and control over the decision-making relevant to one's own life has been described by researchers as a loss of self-esteem and a diminution of self [38-40]. In contrast, being able to do meaningful activities with the support of the digital photo diary and relatives as support is associated with maintaining a sense of self $c f$. [38]. Our interpretation and conclusion of the results is that the factors, Sense of autonomy, Sense of self-esteem and Sense of trust all relate to the second and the third aspect of self $c f$. [36].

Sense of autonomy is an important dimension of the usage of the digital photo diary. Autonomy is more or less related to independence and can be seen as the individual person having the ability to make significant decisions regarding his or her life [41]. As the cognitive impairments of a person suffering from dementia result in loss of autonomy, it is crucial to support and maintain the autonomy of these persons. It seems that the caregivers' perceptions of the usage of the assistive digital device, notably, that AT has the potential to help to maintain the autonomy of people with dementia corresponds to the findings of Powell [42], who reported that carers expressed a general enthusiasm for the benefits, such as gains in or the retention of autonomy when using new information and communication technologies among people with dementia. 
The second factor from the factor analysis and also rated with the lowest mean value, indicating that Sense of selfesteem was measured as an important outcome when using the digital photo diary. When considering the person with dementia taking photos and viewing uploaded photos, both these activities alone or in a familiar atmosphere in the company of and with the assistance of a relative, were perceived to be acts that would strengthen the person's selfesteem. This corresponds with the findings of Sabat and Harre [43], who found that, when positive social interaction took place and there was an opportunity for self-expression, self-esteem was supported. According to Baumeister and Twenge [44], who stressed that having close and meaningful human relationships are crucial parts of the self, one can assume that the relatives' contribution is of great importance for the usage of the digital photo diary to be meaningful for the person with dementia. One study [45] reported that the relatives play an important role as a trigger for people suffering from dementia to be able to re-construct their memory through conversation. The results of our study can be interpreted in the same way: by taking photos and talking about the day's events, the life-story of that one day, for that person, through an active interaction with others and relatives, it is perceived that the person with dementia would be able to retain a sense of self-identity and to recount the story that is important for himself/herself.

There were some differences between how different professional groups perceived the usage of the camera and viewing the uploaded photos. A notable trend was that the occupational therapists, physiotherapists, assistant nurses tended to have similar views on different issues. For example, both Sense of self-esteem when wearing the camera and smart phone at home and outside, and Sense of autonomy when viewing and sorting photos on the computer alongside a relative, were measured in the same way by these professionals.

A possible explanation is that assistant nurses are the professional group working most closely with the people with dementia, giving them a particular insight into the everyday lives of the sufferers while occupational therapists and physiotherapists, because of the nature of their job, tend to focus on rehabilitation challenges. A notable difference is that care administrators, care developers and project leaders tended to have significantly different views on the use of the camera compared to occupational therapists, physiotherapists and assistant nurses. These differences are difficult to explain.

The above-discussed results of differences between positions raises a considerable number of questions about how the differences can be explained, however we do not have enough information in our results to make qualified assumptions.

\section{METHODOLOGICAL CONSIDERATIONS}

The investigation reported here focused on caregivers' perceptions of how persons with mild dementia are likely to experience the usage of a digital photo diary. When discussing the results it must be considered that none of the participants had actually seen the digital photo diary in operation; it was introduced to them via the fictive scenario of Hilda. Nevertheless, we think that the structured way of using a scenario involving a person with dementia (Hilda) and the detailed description of the assistive digital device being used ought to guarantee the uniformity of the responses. By using fictive scenarios of this kind it is possible to perceive the use of an assistive digital device as has been discussed by Fung et al., [46]. However, it is also likely that the way the participants responded may have been influenced by the way the scenario was presented. It is therefore reasonable to assume that the results might have been different if the age, gender and the context of the person taking centre-stage in the scenario were different.

In the evaluation of the digital photo diary considered in this investigation, the usages of the camera and of the viewing function were at the first FA evaluated separately. But the fact is that the two situations for use of the digital photo diary are dependent on each other. The reason for reducing some of the variables after the first FA was made was to have the possibility to make a comparison of the two situations for use of the device. It seems reasonable to reduce the aforementioned adjectives due to their complexity as concepts in the colloquial language and they were also very similar to some other adjectives. The excluded bipolar adjectives were Satisfied/Dissatisfied, Confirmed/Unconfirmed, Cherished/Abandoned, Energetic/Lethargic and Cosy/ Worse.

In addition, the labelling of factors is always a matter of interpretation, and therefore, there is an inherent risk of misinterpretations being made. This risk was handled by discussing the interpretations thoroughly between the authors.

\section{CONCLUSIONS}

A representative group of professional caregivers working with people with dementia perceive the use of the digital photo diary to possibly support autonomy and independence for persons living with dementia. Thus, caregivers have an overall positive view that supports a further development of the digital assistive photo diary. The next step is to evaluate the use of the digital photo diary with persons living the experience of mild dementia in order to find out their perspectives of using it and then compare the findings of both studies.

\section{ACKNOWLEDGEMENTS}

This work was supported by the eHealth Innovation Centre (EIC) at Department of Health Science at Luleå University of Technology and the MemoryLane research project, co-funded by the European Regional Development Fund (Mål-2). We would like to thank the participants for their contributions to the study.

\section{CONFLICT OF INTEREST}

Declared none.

\section{REFERENCES}

[1] Ambient Assisted Living Roadmap of the EU's seventh framework programme Ambient assisted living roadmap. 2010; Available at: http:// www.aaliance.eu. [Accessed October 1, 2011]

[2] Topo P. Technology studies to meet the needs of people with dementia and their caregivers - A literature review. J Appl Gerontol 2009; 28(1): 5-37.

[3] Kitwood T. Dementia reconsidered; the person comes first Buckingham: Open University Press 1997. 
[4] Sävenstedt S, Sandman PO, Zingmark K. The duality in using information and communication technology in elder care. J Adv Nurs 2006; 56(1): 17-25.

[5] Gilmour JA, Huntington AD. Finding the balance: Living with memory loss. Int J Nurs Pract 2005; 1: 118-24.

[6] Langdon S, Eagle A, Warner J. Making sense of dementia in the social world: A qualitative study. Soc Sci Med 2007; 64: 989-1000.

[7] Mok E, Lay C, Wong F, Wan P. Living with early-stage dementia: The perspective of older Chinese. J Adv Nurs 2007; 59(6): 591600

[8] Phinney A, Chaudhury H, O'Connor D. Doing as much as I can do: The meaning of activity for people with dementia. Aging Ment Health 2007; 11(4): 384-93.

[9] McKeown J, Clarke A, Repper J. Life story work in health and social care: systematic literature review. J Adv Nurs 2006; 55(2): $237-47$.

[10] Angus J., Bowen S. Quiet please, there's a lady on stage: Centering the person with dementia in life story narrative.J Aging Stud 2011; 25(2): 110-7.

[11] Clarke A., Hanson EJ, Ross H. Seeing the person behind the patient: Enhancing the care of older people using a biographical approach. J Clin Nurs 2003; 12(5): 697-706.

[12] Meninger $H$. Narrative ethics in nursing for persons with intellectual disabilities. Nurs Philos 2005; 2(2): 173-88.

[13] Bassett R, Graham JE. Memorabilities: Enduring relationships, memories and abilities in dementia. Ageing Soc 2007; 27(4): 53354.

[14] Moore J. Placing home in context. J Environ Psychol 2000; 20(3): 207-17.

[15] Oswald F. Home and identity in late life: International perspectives. In: Rowles GD, Chaudhury H. Eds. Dimensions of the meaning of home in later life. New York: Springer 2005; pp. 21-45.

[16] Haak M, Fänge A, Iwarsson S, Ivanoff SD. Home as a signification of independence and autonomy: Experiences among old Swedish people. Scand J Occup Ther 2007; 14(1): 16-24.

[17] Bowes A, McColgan G. Smart technology and community care for older people: innovation in West Lothian, Scotland. Edinburgh, Department of Applied Social Science, University of Stirling 2006.

[18] Duggan S, Blackman T, Martyr A, Van Schaik P. The impact of early dementia on outdoor life. Dementia 2008; 7(2): 191-204.

[19] Cahill, S., Begley, E., Faulkner, J., Hagen, I. It gives me a sense of independence - Findings from Ireland on the use and usefulness of assistive technology for people with dementia. Technol Disabil 2007; 19(2/3): 133-42.

[20] Sandman L. On the autonomy turf. Assessing the value of autonomy to patients. Med Health Care Philos 2004; 7(3): 261-8.

[21] Emiliani PL. Assistive Technology (AT) versus Mainstream Technology (MST): The research perspective. Technol Disabil 2006; 18(1): 19-29.

[22] Lofqvist C, Nygren C, Széman Z, Iwarsson S. Assistive devices among very old people in five European countries. Scand J Occup Ther 2005; 12(4): 181-92.

[23] Soar J, Seo Y. Health and aged care enabled by information technology. Ann NY Acad Sci 2007; 1114: 154-61.

[24] Cahill S, Macijauskiene J, Nygård AM, Faulkner JP, Hagen I. Technology in dementia care. Technol Disabil 2007; 19: 55-60.

[25] Magnusson L, Hanson E, Borg M. A litterature review study of information and comunication technology as a support for frail older people living at home and their family carers. Technol Disabil 2004; 16: 223-35
[26] Harrefors C, Axelsson K, Sävenstedt S. Using assistive technology services at differing levels of care: Healthy older couples' perceptions. J Adv Nurs 2010; 66(7): 1523-32.

[27] Nygard L. The use of everyday technology by people with dementia living alone: Mapping out the difficulties. Aging Ment Health 2007; 11(2): 144-55.

[28] Kikhia B, Hallberg J, Synnes K, ul Hussain Sani Z. Context-aware life-logging for persons with mild dementia. Proceedings of the annual international conference of the IEEE Engineering in Medicine and Biology Society: EMBC; 2009 Sep 3 - 6; Minneapolis, Minnesota, USA 2009; 6183-6.

[29] Björneby S, Topo P, Holthe T. Technology, ethics and dementia. A guidebook on how to apply technology in dementia care. Norway, Norwegian Centre for Dementia Research 1999.

[30] Zwijsen SA., Niemeijer AR., Hertogh CM. Ethics of using assistive technology in the care for community-dwelling elderly people: An overview of the literature. Aging Ment Health 2011; 15(4): 419-27.

[31] Osgood C, Suci G, Tannenbaum P. The measurement of meaning. Illinois, Board of Trustees of University of Illinios 1957.

[32] Sanders S. Development of a tool to measure subjective time experience. Nurs Res 1986; (35): 178-82.

[33] Norbergh KG, Helin Y, Dahl A, Hellzén O, Asplund K. Nurses' attitudes towards people with dementia: The semantic differential technique. Nurs Ethics 2006; 13(3): 264-74.

[34] Hellzén M, Lind I, Dahl A, Hellzén O. Psychiatric nurses' attitudes towards identified inpatients as measured by the semantic differential technique. Scand J Caring Sci 2005; 19(1): 12-9.

[35] Tabachnick B, Fidell L. Using multivaiate statistics. Boston, Allyn \& Bacon 2001

[36] Sabat SR. Surviving manifestations of selfhood in Alzheimer's disease: A case study. Dementia 2002; 1(1): 25-36.

[37] Engstrom M, Lindqvist R, Ljunggren B, Carlsson M. Staff members' perceptions of a ICT support package in dementia care during the process of implementation. J Nurs Manag 2009; 17(7): 781-9.

[38] Harris PB, Sterin G. Insider's perspective: Defining and preserving the self of dementia. J Ment Health Aging 1999; 5(3): 241-56.

[39] Clare L. We'll fight it as long as we can: coping with the onset of Alzheimer's disease. Aging Ment Health 2002; 6(2): 139-48.

[40] Holst G, Rahm-Hallberg I. Exploring the meaning of everyday life for those suffering from dementia." Am J of Alz Dement 2003; 18(6): 359-65.

[41] van Thiel G, van Delden J. The principle of respect for autonomy in the care of nursing home residents. Nurs Ethics 2001; 8(5): 41931.

[42] Powell J, Gunn L, Lowe P, Sheean B, Griffiths F, Clarke A. New networked technologies and carers of people with dementia: An interview study. Ageing Soc 2010; 30(6): 1073-88.

[43] Sabat SR, Harré R. The construction and deconstruction of self in Alzheimer's disease. Ageing Soc 1992; 12(4): 443-61.

[44] Baumeister RF, Twenge JM. The social self. In Millon T, Lerner MJ. Eds. Handbook of psychology. New York, Chichester; Wiley. 2003; 5: 327-52.

[45] Cohen-Mansfield J, Golander H, Arnheim G. Self-identity in older persons suffering from dementia: Preliminary results. Soc Sci Med 2000; 51(3): 381-94.

[46] Fung AWT, Lam LCW, Lui VWC. Could hypothetical scenarios enhance understanding on decision for life-sustaining treatment in non-demented Chinese older persons? Aging Ment Health 2010; 14(8): 994-9. 